\title{
1 Repeated observations of Cetaceans and Carcharhiniformes associations in the Red Sea
}

2 Till Röthig ${ }^{1}$, Julia L.Y. Spaet ${ }^{1}$, Alexander Kattan ${ }^{1}$, Isabelle K. Schulz ${ }^{1}$, May Roberts ${ }^{1}$, Anna Roik ${ }^{1}$,

3 Christian R. Voolstra ${ }^{1}$

4

\section{Affiliations:}

$6 \quad{ }^{1}$ Red Sea Research Center, King Abdullah University of Science and Technology (KAUST), Thuwal, Saudi

$7 \quad$ Arabia

9 Shark-cetacean aggregations and associations of false killer whales (Pseudorca crassidens) with other 10 cetaceans have been reported previously (e.g. Heithaus 2001, Baird et al. 2008). However, this is the first

11 description of non-aggressive associations of P. crassidens with non-cetaceans.

12 Here we report encounters of P. crassidens associated with silky sharks (Carcharhinus falciformis) at 13 different reef sites of the Farasan Banks, Red Sea, Saudi Arabia in 2014. On August 13 a group of 17+ $P$.

14 crassidens ( $2-4 \mathrm{~m}$ body length; including one juvenile, $<2 \mathrm{~m}$ ) (Fig.1a) approached a dive boat and spent 15 about 45 minutes interacting with 20 snorkelers at "Dohra Island Reef" (194 49'16.80"N, 39 54'6.75"E).

16 The group was accompanied by $6+$ C. falciformis $(1.6-2 \mathrm{~m}$, Fig. $1 \mathrm{~b})$, which remained in close proximity $17(\sim 15 \mathrm{~m})$ to snorkelers and whales for about 20 minutes (Fig.1c).

18 On August 19, a group of 15 divers was approached by 8 P. crassidens individuals $(2-4 \mathrm{~m}$; including 1

19 juvenile <2m), followed by 2 C. falciformis (1.6-2m) at "Old Fantasy Island Reef" $\left(19^{\circ} 38^{\prime} 36.39^{\prime} \mathrm{N}, 40^{\circ}\right.$

20 1'10.66"E). Both encounters lasted for 10 and 2 minutes, respectively. During both occasions neither

21 whales nor sharks displayed signs of distress or rejection towards each other's presence. An additional

22 sighting of a $P$. crassidens group accompanied by $C$. falciformis on June 18 in the southern Farasan Banks

23 was reported by the dive base (Dream-Divers, KSA), but no details are available.

24 The possible benefits of associations between false killer whales and silky sharks remain unclear and the 25 aggregations might be random without direct benefits for the different species. However, shared feeding 26 grounds might provide an explanation for the presence of multi-species groups. On August 13, an 27 individual of P. crassidens carried a prey fish (supplementary video). Even though no feeding was directly 
28 observed, prey indicates a previous hunting event and may suggest the possibility of a foraging association

29 (sensu Lukoschek and McCormick, 2002).

30

31 ACKNOWLEDGEMENTS

32 We thank Frederico Oreamuno and Jhonathan Rojas for video and photo material and Dream-Divers for

33 field and data support.

34

35 Conflict of Interest: The authors declare no conflict of interest.

36

37

38

39

40

41

42

43

44

45

46

47

48

49

\section{FIGURE LEGEND}

51 Fig.1. (a) Pseudorca crassidens, 19.08 .14 (b) Carcharhinus falciformis, 13.08.14 (c) P. crassidens (front), 52 C. falciformis (background), 13.08.14. 